\title{
Traceable Ecosystem and Strategic Framework for the Creation of an Integrated Pest Management System for Intensive Farming
}

\author{
Miguel Ángel López, Juan Manuel Lombardo*, Mabel López, David Álvarez, Susana \\ Velasco, Sara Terrón
}

Fundación I+D del Software Libre (FIDESOL), Granada (Spain)

Received 27 April 2020 | Accepted 29 July 2020 | Published 7 August 2020

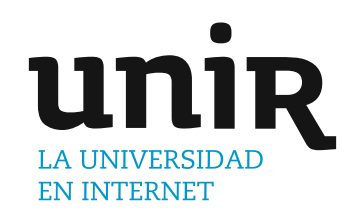

\section{ABSTRACT}

The appearance of pests is one of the major problems that exist in the growth of crops, as they can damage the production if the appropriate measures are not taken. Within the framework of the Integrated Pest Management strategy (IPM), early detection of pests is an essential step in order to provide the most appropriate treatment and avoid losses. This paper proposes the architecture of a system intensive farming in greenhouses featuring the ability to detect environmental variations that may favour the appearance of pests. This system can suggest a plan or treatment that will help mitigate the effects that the identified pest would produce otherwise. Furthermore, the system will learn from the actions carried out by the humans throughout the different stages of crop growing and will add it as knowledge for the prediction of future actions. The data collected from sensors, through computer vision, or the experiences provided by the experts, along with the historical data related to the crop, will allow for the development of a model that contrasts the predictions of the actions that could be implemented with those already performed by technicians. Within the technological ecosystems in which the Integrated Pest Management systems develop their action, traceability models must be incorporated. This will guarantee that the data used for the exploitation of the information and, therefore for the parameterization of the predictive models, are adequate. Thus, the integration of blockchain technologies is considered key to provide them with security and confidence.

\section{KEYWORDS}

\author{
Integrated Pest \\ Management, IPM, \\ Computer Vision, \\ Machine Learning, \\ Artificial Intelligence, \\ Blockchain, Intensive \\ Farming, Greenhouses.
}

DOI: 10.9781 /ijimai.2020.08.004

\section{INTRODUCTION}

P RESERVING the crops and increasing production is a constant concern of vegetable growers. The appearance of diseases and external agents such as fungi, bacteria, insects, and other forms of plant or animal life can be a threat that jeopardizes the crops, and hence the livelihood of growers and their families. This does not only put the primary sector groups at risk, but it also has a direct impact on the economy of a country and compromises the nutritional security of the inhabitants of the countries that are dependent on the supply of such goods.

In order to counter the various pests that endanger the supply of food and agricultural commodities, a wide range of products called agrochemicals, phytosanitary products or pesticides are used. These highly toxic synthetic compounds include chemical components that can eliminate pests and vectors of communicable diseases while avoiding damage to the crops [1], [2].

Given the controversy over the permissiveness in the use of certain chemicals, which are banned in some countries [3] and exploited in others [4], epidemiological studies show that human exposure to these

\footnotetext{
* Corresponding author.

E-mail address: jmlombardo@fidesol.org
}

agrochemicals may produce adverse effects on health [5]-[10].

In addition, the excessive or indiscriminate employment of agrochemicals can lead to a decrease in their own efficiency, generating just the opposite effect to the one desired [11], [12]. These substances can accelerate the development of resistant weeds and favour the increase of the pest population. Such resistance is more likely to occur in genetically modified crops, as they tolerate a very narrow spectrum of herbicides [13]. This makes rotation difficult due to the depletion of the biodiversity of agricultural land [14], which causes the development of persistent weeds, insect pests and pathogenic bacteria that evolve and spread rapidly [15]. The latter may lead to use more toxic profile herbicides [16] that will most probably turn detrimental to the environment [17]. The grower gets trapped in a harmful and unsustainable circle given that those varieties require a greater contribution of fertilisers, water and pesticides, which increases the dependence on the use of synthetic products and may lead to a decrease in production [18], [19].

Adding to the drawbacks implied in the application of the products mentioned above, such agricultural waste is the most widespread, dispersed and difficult to control, and becomes one of the main sources of contamination of groundwater, surface water and soil. This serious environmental problem is also transferred to the population of developed countries where the problems of food poisoning have also had a negative social and economic impact [20], [21]. 
The desire of consumers to obtain food free of harmful chemicals, together with the need for a real system of sustainable and organic farming, has triggered the creation of an Integrated Pest Management system (IPM), as a scientific paradigm in safe food production. This procedure allows to manage the agroecosystem favouring the grower through the observation of environmental aspects that enables the incorporation of alternative non-chemical measures or techniques to pesticides. Integrated Pest Management "emphasises the growth of a healthy crop with the least possible disruption to agro-ecosystems and encourages natural pest control mechanisms" [22].

The development of populations of harmful organisms is avoided by the preventive application of those control measures, which minimizes risks to both human health and the environment. Therefore, it is essential to accurately detect different pest infestations when they are just emerging and to establish a control and prevention strategy that is as effective as possible. In this sense, it is essential to identify the problem correctly. However, carrying out these actions involves several difficulties. An adequate diagnosis of the situation relies on historical data obtained about the area, the knowledge of growers, or the observations and sampling conducted by technicians on the crop areas [23] on a weekly or biweekly basis [24].

Furthermore, global trade and climate change favour the appearance of new species and the displacement of habitats, making the future spread of harmful organisms unpredictable [25]. Accordingly, early detection of pests and the minimum application of plant protection products are critical requirements to avoid an increase in pollution and obtain less chemically treated though healthier agricultural products.

In response to these demands, different technological solutions have emerged for the detection of pests using intelligent aircraft. Some studies, such as that of Hunt et al. [26], propose a pest detection system based on sensors and unmanned aircraft systems to acquire high-resolution images of potato crops. To check if a crop is infected, these authors analyse the nitrogen content in the leaves of the plants, allowing them to act quickly. In this regard, Stumph et al. [27] evaluate an automatic system for the early detection of pests that uses unmanned aerial vehicles equipped with cameras too, ultraviolet technology and algorithms based on computer vision. Likewise, Shamshiri et al. [28] study the behaviour of the pests in oil palm plantations drawing on a drone equipped with sensors. Its aim is the design of three controllers (PID, LQR, and LQR plus observer) that allow for automatic insects detection. Finally, Psirofonia et al. [29] carry out a study on three cases where a drone, in combination with electronic traps, is used for pest detection and spraying of olive and palm trees.

In other studies, researchers also use computer vision techniques and a sensor system to detect pests in greenhouse crops [30]-[32]. Huddar et al. [33] propose an algorithm for pest detection based on image processing that has be tested on outdoor crops as well as in greenhouses. Their algorithm is $96 \%$ accurate in detecting whiteflies, one of the most damaging pests to crops. Studies such as that of Nguyen and Nansen [34] use data provided by hyperspectral sensors to feed an algorithm that classifies the risk of pest infestation in spinach and cabbage plantations.

In this work, we present the architecture of an automatic system based on sensors and cameras for the identification, recording, and tracking of different pests that may affect intensive farming crops in greenhouses. In section II, the proposed architecture and its components are defined and explained in detail. The discussion about this architecture is exposed in section III. Finally, the conclusions and future work are considered in section IV.
II. Material and Methods

Our research aimed at creating a system that is able to autonomously monitor the state of crops, analyse their evolution, enable early detection of pests, and forewarn the emergence of new ones as well as their likely transmission vectors.

The design shown corresponds to an Integrated Pest Management system harnessing the capacity to collect information from various sources, analyse such data, extract characteristics, or draw patterns for a better understanding of the behaviour of external agents that may affect the development of crops. Among these external agents are mainly insects or pests, and all those climatic, environmental or biological factors influencing the growth of plants. In this way, a predictive plan can be created to enable preventive action, which will reduce the application of agrochemicals significantly and will contribute to the long-term sustainability of the agri-food system.

This section describes the IPM strategies and techniques that have been applied to determine each of the system components for the intelligent acquisition, processing, and evaluation of the information required to model the system architecture. The data provided and their sources, which are also essential to create our predictive pest management model, are considered.

Research conducted by Fidesol has determined that the parameters described in Table I are the most appropriate ones to be considered when addressing an IPM system for intensive crops farming.

taBle I. Influential Parameters in the Appearance of Pests and Other Elements Harmful to Plants

\begin{tabular}{|c|c|}
\hline Parameter & Description \\
\hline Soil temperature $\left({ }^{\circ} \mathrm{C}\right)$ & Soil temperature at root level \\
\hline Soil moisture $(\% \mathrm{RH})$ & Soil moisture at root level \\
\hline $\begin{array}{l}\text { Soil electrical conductivity } \\
(\mathrm{s} / \mathrm{m})\end{array}$ & Soil electrical conductivity at the root level \\
\hline Solar radiation $(\mathrm{W} / \mathrm{m} 2)$ & Direct and diffuse radiation \\
\hline Air temperature $\left({ }^{\circ} \mathrm{C}\right)$ & Air temperature \\
\hline Air humidity $(\% \mathrm{RH})$ & Relative air humidity \\
\hline Precipitation $(\mathrm{mm} / \mathrm{h})$ & Water content in precipitation \\
\hline Altitude $(\mathrm{m})$ & The height of the area in relation to sea level \\
\hline Atmospheric pressure $(\mathrm{Pa})$ & Atmospheric pressure outside the greenhouse \\
\hline Wind direction $\left({ }^{\circ}\right)$ & Wind direction \\
\hline Wind speed $(\mathrm{m} / \mathrm{s})$ & Wind speed \\
\hline Surface leaf temperature $\left({ }^{\circ} \mathrm{C}\right)$ & Surface leaf temperature \\
\hline Stem thickness (mm) & Stem thickness \\
\hline Nitrates (ppm) & Nitrate levels in the soil \\
\hline Potassium (ppm) & Potassium level in the soil \\
\hline $\mathrm{CO} 2(\mathrm{ppm})$ & CO2 level in the air \\
\hline Soil tension $(\mathrm{kPa})$ & $\begin{array}{l}\text { The effort that the roots have to make to } \\
\text { extract the water they need from the soil }\end{array}$ \\
\hline $\mathrm{PH}(\mathrm{pH})$ & PH level of the soil \\
\hline Soil type & Soil type classification \\
\hline Property & Property where the cultivation takes place \\
\hline Agricultural area & Greenhouse where the cultivation takes place \\
\hline Plant genus & Type of plant \\
\hline Seed variety & Varieties of seeds \\
\hline Grafting & Kind of graft \\
\hline Plantation type & Transplant form \\
\hline Row distance $(\mathrm{m})$ & Distance between rows \\
\hline Plants distance $(\mathrm{m})$ & Distance between plants \\
\hline Cycle & Time cycle when cultivation takes place \\
\hline Previous sowing & Plant previously sown \\
\hline Sample date & Date on which the sample is collected \\
\hline
\end{tabular}




\section{A. IPM Strategies and Techniques}

The analysis of the state of the plants, together with the study of the growth rate of the pest populations is intended to develop control strategies aimed at reducing the use of chemical controls, through activities of surveillance, biological and chemical control.

The main application of IPM took place in agriculture, although the benefits of its implementation in other fields have been proven later, such as in the control of weeds, diseases, and other plagues that can damage crops, gardens and other urban spaces [35]-[37].

With the adoption of the IPM, activities are now focused on preventive monitoring and analysis of crops to reduce the populations of harmful organisms, using appropriate cultivation techniques and ecological measures. The IPM prioritizes non-chemical methods so that professional pesticide users opt for practices and products that pose the least risk to human health and the environment. Therefore, after a regular inspection on the appearance of a specific pest, its growth is observed and, if it exceeds a certain threshold, the action is executed by applying a preferably biological treatment [22]. Only when the control results are not satisfactory, the appropriate plant protection products are applied for each case. A general outline of the IPM system is shown below in Fig. 1.

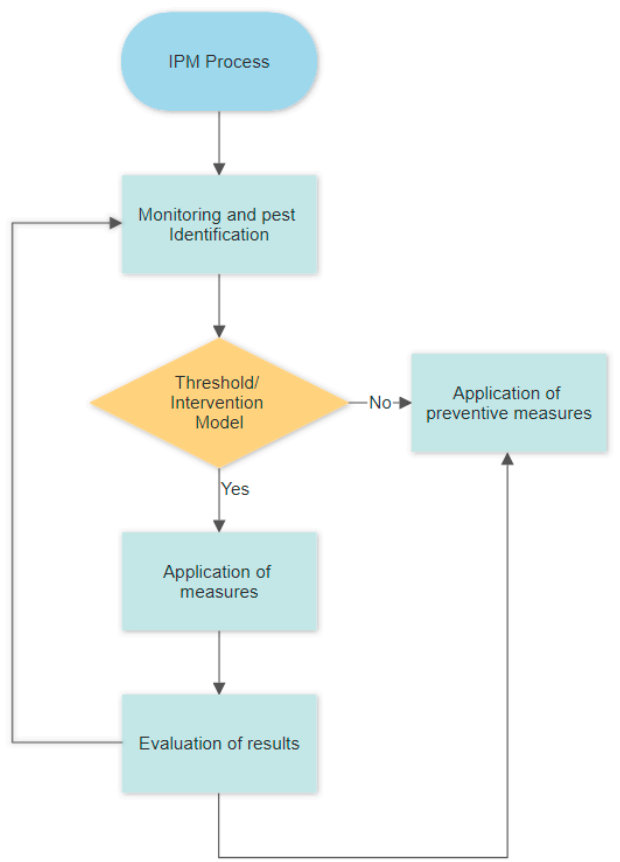

Fig. 1. General outline of the steps identified for the IPM system.

In this research work, for the adoption and correct compliance of IPM strategy, the following steps are considered to achieve the adequate environmental sanitary conditions and avoid the proliferation of harmful organisms:

- Monitoring and identification of pests. It is worth mentioning that it is not necessary to reduce the population of all insects that may appear in pest control. Some of them are harmless and even beneficial. It is essential to identify and differentiate them in order to act according to the threshold defined within the framework for action agreed at the national level. Through monitoring and identification, the possibility of unnecessary or incorrect use of pesticides is removed.

- Checking the action threshold / intervention model. Before taking any control action, it should be observed whether a threshold has been reached where conditions indicate that pest control measures should be taken.
- Action/application of control measures. Action is taken when the pest has been monitored and identified, and the control thresholds have been exceeded even following the application of preventive methods that have not proved effective enough in controlling the pests and diseases. The application of cultural, physical or biological methods, which pose the least risk to health and the environment, such as trapping or weeding, always comes first in the implementation of control measures. If, after application of the relevant measures, the results continue to exceed the action thresholds, a switch to the use of chemicals shall be made by selecting those authorised for effective control. These chemicals should be as much compatible as possible with non-target organisms to avoid harm to insects for natural pest control and others that are also beneficial, such as bees [38].

- Evaluation of results. At this step, the results of the prevention or control actions taken are assessed in order to know their degree of effectiveness or unsought effects, which will help to determine the appropriate actions if a similar case arises in the future. In addition, a report will be produced whose main purpose is to verify the degree of effectiveness of the measures, identify trends through the analysis of results, and include the observations deemed necessary.

- Prevention. One of the first actions of pest control in IPM strategy is the application of preventive measures to prevent pests from becoming a threat. Some of these measures are based on the following methods: crop rotation, the use of appropriate cultivation techniques, or the selection of crop species resistant to pests. These methods are usually profitable in the long-term as well as friendly with humans and the environment [39]. This type of measures builds the framework of the first actions to be implemented for the prevention or elimination of harmful organisms.

Each of the steps that make up the IPM have been considered in the architecture design proposed in this work, as detailed in the following section.

\section{B. Proposed Architecture}

The architecture proposed in this work is defined within the framework of Directive 2009/128/ EC on Sustainable Use of Pesticides of the 21 October 2009, based on the principles of the IPM that consider "all available plant protection methods and subsequent integration of appropriate measures that discourage the development of populations of harmful organisms and keep the use of plant protection products and other forms of intervention to levels that are economically and ecologically justified and reduce or minimize risks to human health and the environment" [22].

Once the correspondence of the approaches and measures of the IPM strategy with the necessary technological components that promote the application of its principles has been identified, the system architecture is described in Fig. 2.

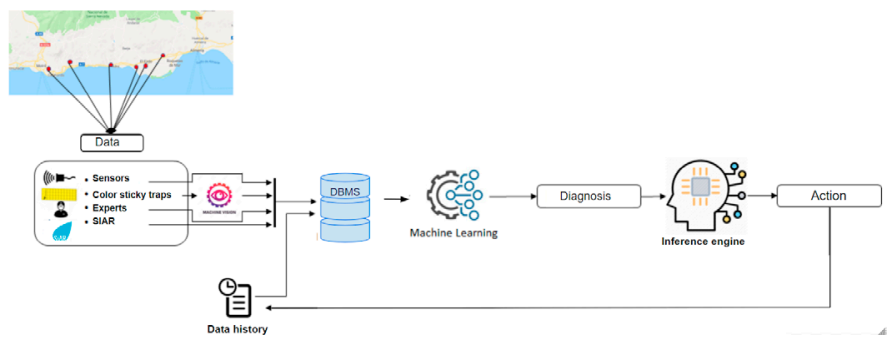

Fig. 2. System architecture.

By relying on the data provided continuously by the different sources and also on the data history, the proposed system is able to early detect incidents that may occur during the life of a crop and 
determine the physiological state from its phenological stage in realtime. All this information flow helps to establish a sound foundation on which to create a predictive system based on machine learning.

However, the implementation of an Integrated Pest Management system is particularly challenging since the information for each plant is not yet fully defined, as is the case with thresholds for all types of pests. There is a need for plant health expertise to help ensure the sustainable and efficient use of plant protection products. The determination of safe and scientifically sound threshold values depends on the place of cultivation and is even a controversial issue among experts [40]. The impressive amount and complexity of variables that intervene in this system to define parasitic phenomena (both of environmental origin and of the crop itself) make it necessary to carry out welloriented and advanced research in which technology and fieldwork are highly relevant. In addition to the parameters considered in the system described here and the knowledge acquired during the learning process of the system itself for this environment over several complete production cycles, the presence of an infestation will be essential to detect accurately its appearance in advance, as well as its level of severity so that the most suitable solution can be adopted in each case.

Regarding the steps that make up the IPM system, the guidelines to create the proposed architecture are explained below.

\section{Monitoring and Identification of Pest}

To enhance the prevention principle of Integrated Pest Management, monitoring and identifying the species that can negatively affect the production of a given crop is essential. In this case, monitoring typically entails a visual process that implies exploring and observing the plants on a regular basis. This type of observation is a time-consuming activity that may result in the pest not being timely detected, but just when the infestation has reached very high levels. The aim of this research work is the early detection of pests through the creation of an intelligent system featuring the ability to monitor and identify the level of infestation by resorting to data acquisition techniques specific to precision agriculture and computer vision.

\section{a) Data Acquisition}

In order to know the status of a crop, it is essential to collect data for subsequent analysis and act on the results obtained. Automatic data collection is a critical step as this generate a more specific view of all the elements that can affect a crop.

- Technical work. The monitoring process is usually performed manually by qualified technicians. This task requires checking the plates used to detect crop pests for at least two hours a day. So, this is not always possible if other more critical tasks arise. For the horticultural plants in the study area, the placement of the plates should be one every $100 \mathrm{~m} 2$, i.e., 100 plates in 1 hectare. The inspection is conducted once or twice a week to examine the species caught and check the growth or decline of the population observed while taking into account the threshold for action. Should this activity be reinforced with automation techniques, better monitoring, early detection and more frequent assessment of the status of the crop will be available.

- Wireless sensor network. It allows to obtain continuously the parameters associated with the crop in real-time, providing greater control of the exploitation and capacity in case of contingencies. It consists of a remote unit with an autonomous power supply that includes a solar panel and battery together with sensors that collect and transfer the environmental information (climate and soil parameters) to other remote unit. The continuous collection of such information becomes a key component of a more accurate early detection mechanism to respond quickly to adverse situations.

It is paramount to take into consideration the implementation of information assurance technologies, both on input devices and sensors. Internet of Things (IoT) devices pose a security challenge since well-established data protection protocols are not yet comprehensively embedded and there is no a "one-sizefits-all" solution. For IoT to be fully exploited, information and communication encryption along with appropriate authentication requests must be implemented. Blockchain technology allows to store encrypted information for each IoT device. A complete security layer will also be provided in the blockchain IoT system so that authentication will be more secure. Blockchain will allow for security and non-repudiation management in IoT sensor networks and the certification of multimedia content assuring the veracity, transparency and security of the information.

- Data mining of external systems. Agricultural information systems are of particular interest as they make it possible to identify a large number of properties, their characteristics, data history, yields, pests, common diseases, monitoring performed, and control measures taken. This type of instrument enables agricultural technicians to record information and observations on the plot. The work of the technicians is time demanding, albeit it is essential since the historical data on the crop resulting from monitoring activities are invaluable for decision-making on the integrated management pest strategy.

- Data from the Agroclimatic Information System (SIAR) [41]. The SIAR network "has more than 460 stations located on irrigated areas in 12 autonomous communities in Spain. This collaborative network has a coverage of $90 \%$ of the irrigable area of the country and allows obtaining meteorological data with an hourly average frequency from one or several stations" [42]. The parameters obtained through this source of information provide value not only in terms of temperature and humidity but also for wind direction and intensity. As a consequence, it is possible to study the spread of a pest on a small (in the same agricultural area) and a large geographical scale (different agricultural areas).

- Computer Vision Systems. Within an automatic identification system, computer vision plays a fundamental role since it allows for the recognition of objects just as the human eye could. The use of this methodology has great potential in identifying insects based on size, shape or colour. In addition, this system is more effective if it describes at what development stage the insects tested are in order to know the status of the pest and act accordingly.

\section{b) Register}

Data sources will be dealt with NoSQL and SQL storage systems for the management of large volumes of unstructured and structured data according to their purpose, so as to reduce query latency in realtime information requests.

\section{c) Sensor Data Normalization}

Data normalization is an essential step for the integration of devices from different manufacturers and therefore offer different data structures. The normalization of the data sent by each device aims to obtain a standard scale in the values, reduce the data structures and achieve standardization, thus avoiding the loss of information and processing errors (Fig. 3). The aim is to transform data into a standard format that allows the exchange and representation of information from different heterogeneous devices [43]. This technique allows us to prepare the data so that the algorithms can model them properly. A difference in the scale of values can cause problems when combining data as characteristics in a model. By fitting in the same distribution within a series of calculations, a more stable behaviour in optimization methods is achieved. 


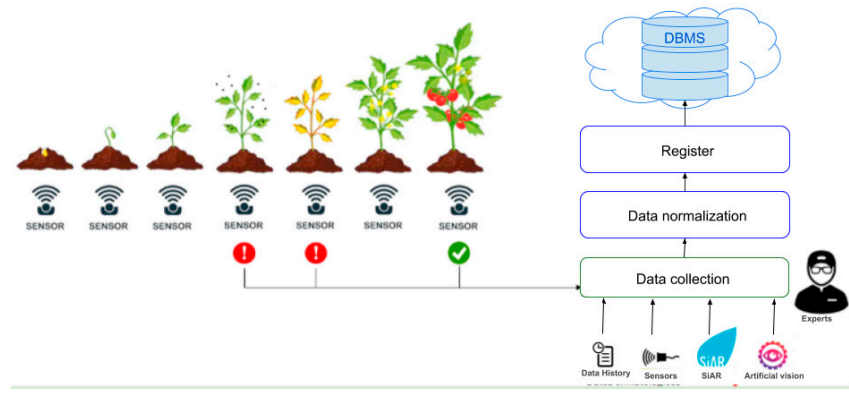

Fig. 3. Monitoring and identification of pests by the system.

\section{d) Processing}

The analysis of the characteristics of the data sets is carried out to limit them and thus avoid working with repeated and irrelevant data. To that purpose, structures are simplified in terms of their dimension and complexity, which improves understanding of the information and performance. The reduction of this dimensionality is also aimed at the segmentation and classification of the data with supervised classification algorithms. This action focuses on avoiding processing errors in the algorithms for which the review is performed in order to eliminate erroneous data by completing the information in the event of sensor failures and generating data that can be verified from nearby stations.

\section{Diagnosis According to Thresholds and Application of Prevention and Control Measures}

Once the information from the different sources has been collected, the anomaly monitoring and identification module can provide an intelligent diagnosis that will be reviewed in the integrated pest management plan and action will be taken, if necessary. The results of such monitoring shall be based on the threshold levels established for each harmful organism in the given region, the specific areas, the crops, the climatic conditions of each plot, and the level of economic damage.

The sighting of a pest does not always imply the need for control since it will not be necessary to take a limiting action if it does not exceed the established threshold of infestation. An inference engine is responsible for making intelligent decisions basing on the knowledge already acquired or on new data registered so that the system feeds back to infer an appropriate diagnosis and determine an action according to the circumstances analysed. The methodology used by the inference engine follows the process presented in Fig. 4.

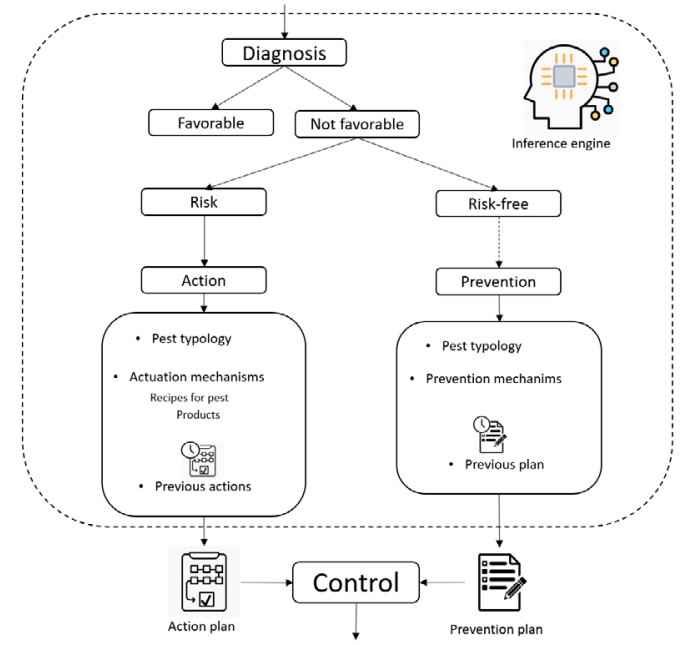

Fig. 4. Inference engine. Evaluation of the input for diagnosis and action or prevention plan.

\section{Evaluation}

Professional users shall check the effectiveness of the measures implemented on the basis of recorded data on prevention, control and monitoring of harmful organisms. All the protection methods applied and the results obtained shall be carefully examined for subsequent introduction into the system (either manually or automatically). The threshold values of the parameters above to which the different prevention and action measures are applied will be reviewed to adjust them as much as possible when the problem that caused them has already been solved.

In addition, the information in the system will be updated with the registration of all the variations in terms of products authorised and expressly approved for cultivation, new developments in innovative products that are healthy and environmentally friendly, as well as with the alterations or additions to legal and health matters. This also ensures that the product meets the quality requirements set.

The large amount of information and learning are processed in a cognitive engine that feeds the inference engine so that the latter can make intelligent decisions based on the knowledge already acquired or on new data. So, the system feeds back to infer a diagnosis that is increasingly accurate and adapted to the circumstances analysed.

\section{DiSCUSSION}

IPM is a fundamental part of all activities involved in the efficient management of a greenhouse. In this system, the detection and classification of insects is a must. The employment of various automatic methods for pest detection in the crop optimizes this task and significantly improves the results.

One of the data collection methods in the architecture proposed in this work begins with insect sampling to assess the status/level of infestation. Some of the research in this area shows the potential of image processing algorithms to count insects captured in traps. In one of the works analysed, a system based on colour heuristics and mathematical morphology is used [44]. This system consists of the delimitation of the region of interest, application of the colour transformations, segmentation based on thresholds, and detection of young whitefly nymphs. Others rely on simple image processing systems, using size, colour, or outline to detect specimens [45]-[47]. It was shown that the count was done faster automatically than manually. Some authors propose a method for identifying whiteflies in greenhouses based on their own algorithm called LOSS [48]. However, this method is later improved by abstracting the position and illumination to achieve a better identification process [49]. Also noteworthy are the works for the detection of aphids [46], [50] and whiteflies [51] in greenhouses using different formulas with which a system based on Support Vector Machines (SVM) will make the classification.

In our project, with the module of pest recognition by computer vision, we try to detect the spectrum that comprises the main harmful organisms causing higher economic losses in agricultural production. The diagnosis of pests will be obtained by studying the level of occupation in the leaves of the plants and their symptoms, by means of the most efficient algorithms of classification based on SVM, as they are the ones providing the best results, which will be evaluated to obtain the highest possible efficiency for each of the insects.

However, it should be noted that different computer vision techniques may not be sufficient for early and high-quality detection. The project incorporates self-adjusting algorithms for acquiring knowledge using machine learning techniques, viewed from a perspective based on agricultural knowledge and the capacity for critical evaluation acquired from the observation of crops development.

In this line and with a multidisciplinary approach that involves 
the observation of plants, the interpretation of images obtained from cameras, and decision-making for early pest detection, research such as that of Boissard [52] focuses on the application of image processing algorithms adapted with machine learning techniques. Some studies use SVM-based algorithms as a classification method [51], [53], [54], cascaded convolutional neural networks [55] or neural learning algorithms together with knowledge-based techniques for an automatic image interpretation system [56]. The system proposed goes further since the learning algorithms used to obtain a pest diagnosis not only act in the computer vision system but also consider the whole set of standardized input data that have been collected from different sources of information in the system.

Recent works use additional components from the precision agriculture that integrate a network of sensors to measure temperature, humidity and light intensity levels in a greenhouse, using image acquisition and computer vision system [57]. Also, in order to control pests, a system of light, relative humidity and soil moisture sensors are usually installed [58]-[61], or underground acoustic sensor nodes with a mathematical simulation model [62].

In the work of Calderón [61], the variables related to environmental conditions such as air temperature, relative humidity, $\mathrm{CO} 2$ concentration, luminosity, wind direction and speed, solar and ultraviolet radiation are studied for monitoring. Likewise, the analysis of soil moisture in multiparametric monitoring for this product is considered of interest [63]. On the other hand, regarding the study of fungal diseases, air temperature and humidity are observed as critical factors [64]. All these parameters have been considered when designing the architecture proposed in this work, together with others also considered such as edaphological, meteorological and indoors environmental parameters, and those relating to the state and characteristics of the plant variety, as well as the location in the greenhouse. As a result, we have more than thirty parameters that allow for a very precise pest detection and control framework that can even help to find new variables that influence the appearance of pests and diseases in crops.

\section{CONCLUSions And Future Work}

Agriculture is at a turning point as it is facing new critical challenges. There is no doubt about the growing need to increase production in order to meet the demands for food. There is also a need to improve production methods and techniques, and obtain higher quality products. In this sense, society demands the integration of agricultural practices that respect human health and the environment, and favour the preservation of heritage for future generations while guaranteeing food security [65].

Integrated Pest Management enables the development of healthy crops by maintaining agroecosystems and promoting pest control mechanisms. The relevance of this system stems from the benefits it provides and its mandatory nature for professional users as far as plant protection products are concerned.

In this paper, our research project has been presented as a system that follows and applies the principles of the IPM. The steps for the implementation of this system are described, and its principles are analysed through the integration of the necessary hardware and software components in each of the steps of the IPM. This allows to build an intelligent system for the early prediction and quick response on intensive farming in greenhouses.

The main contribution of this work is the development of an automated, secure and integrated system that can provide accurate information on pests affecting plants, predict their appearance and facilitate, through a system of recommendations, the necessary preventive and control measures to be implemented in an effective and environmentally friendly way. By considering environmental factors, appearance and insect activity, it is possible to predict the appearance of pests and diseases in an uncontrolled agricultural environment and apply the most appropriate measure in each case.

Work will continue in the search for the most effective algorithms that allow for the diagnosis of diseases and pests through the large volume of parameters provided on a continuous basis along with the building of the knowledge base that will feed the system. It will be necessary to identify the limitations imposed by the presence of elements that disrupt and alter the measurements of the system, e.g. the presence of dirt, excessive light or silence in the data acquisition system that have provided erroneous data in the diagnosis provided. Finally, the study of the behaviour of pests and diseases will be extended so that the proposed system will become more accurate across different experimental locations resulting from the comparison and improved results from real situations. In this way, new influencing factors can be identified, and those that are more unpredictable and represent a threat to the development of both this and any other type of crop can be pointed out.

\section{REFERENCES}

[1] O. Díaz and C. R. Betancourt Aguilar, "Los pesticidas; clasificación, necesidad de un manejo integrado y alternati- vas para reducir su consumo indebido: una revisión," Revista Científica Agroecosistemas, vol. 6, no. 2, pp. 14-30, 2018.

[2] A. Ferrer, "Intoxicación por plaguicidas," Anales del Sistema Sanitario de Navarra, vol. 26, no. SUPPL. 1, pp. 155-171, 2003.

[3] European Comission, Regulation (EU) No 540/2011 of 25 May 2011 implementing Regulation (EC) No 1107/2009 of the European Parliament and of the Council as regards the list of approved active substances. 2011.

[4] K. Zhang et al., "Susceptibility of Sogatella furcifera and Laodelphax striatellus (Hemiptera: Delphacidae) to Six Insecticides in China," Journal of Economic Entomology, vol. 107, no. 5, pp. 1916-1922, 2014.

[5] A. Samsel and S. Seneff, "Glyphosate, pathways to modern diseases IV: Cancer and related pathologies," Journal of Biological Physics and Chemistry, vol. 15, no. 3, pp. 121-159, 2015.

[6] M. F. Fernández, M. F. Fernández, J. A. López-Medina, V. Mustieles, and N. Olea, "Obesógenos ¿Una nueva amenaza para la salud pública?," Revista de Salud Ambiental, vol. 17, no. 1, pp. 93-99, 2017.

[7] R. Gerber et al., "Bioaccumulation and human health risk assessment of DDT and other organochlorine pesticides in an apex aquatic predator from a premier conservation area," Science of the Total Environment, vol. 550, pp. 522-533, 2016.

[8] A. Sabarwal, K. Kumar, and R. P. Singh, "Hazardous effects of chemical pesticides on human health-Cancer and other associated disorders," Environmental Toxicology and Pharmacology, vol. 63, pp. 103-114, 2018.

[9] E. Nava-Pérez, C. García-Gutiérrez, J. R. Camacho-Báez, and E. L. Vázquez-Montoya, "Bioplaguicidas: Una opción para el control biológico de plagas," Ra Ximhai, vol. 8, no. 3, pp. 17-29, 2012.

[10] A. Samsel and S. Seneff, "Glyphosate, pathways to modern diseases III: Manganese, neurological diseases, and associated pathologies," Surgical Neurology International, vol. 6, no. 1, 2015.

[11] A. B. Figueras, "Representación social del riesgo en la costa de Oaxaca: Agrotóxicos, salud y medio ambiente," Arxiu d'Etnografia de Catalunya, pp. 115-149, 2020.

[12] S. Ramírez, "Las investigaciones de salud pública en Latinoamérica. Reflexiones desde el Sur global," Revista Facultad Nacional de Salud Pública, vol. 37, no. 1, pp. 106-113, 2019.

[13] S. Bonny, "Genetically Modified Herbicide-Tolerant Crops, Weeds, and Herbicides: Overview and Impact," Environmental Management, vol. 57, no. 1, pp. 31-48, 2016.

[14] R. S. Cavalcanti, A. Moino Jr, G. C. Souza, and A. Arnosti, "Evaluation of the effect of pesticides on the development of the fungus Beauveria Bassiana (BALS)," VUILL. Arquivos do Instituto Biológico, vol. 69, no. 3, pp. 17-22, 2002.

[15] M. A. Altieri, "The ecological impacts of transgenic crops on agroecosystem health," Ecosystem Health, vol. 6, no. 1, pp. 13-23, 2000. 
[16] J. R. Lamichhane et al., "Integrated weed management systems with herbicide-tolerant crops in the European Union: Lessons learnt from home and abroad," Critical Reviews in Biotechnology, vol. 37, no. 4, pp. 459475, 2017.

[17] S. E. Jacobsen, M. Sørensen, S. M. Pedersen, and J. Weiner, "Feeding the world: Genetically modified crops versus agricultural biodiversity," Agronomy for Sustainable Development, vol. 33, no. 4, pp. 651-662, 2013.

[18] H. Elver, "Promotion and protection of human rights: human rights questions, including alternative approaches for improving the effective enjoyment of human rights and fundamental freedoms," Interim report of the Special Rapporteur on the right to food, pp. 2-23, 2017.

[19] J. E. García G., "Cultivos genéticamente modificados: las promesas y las buenas intenciones no bastan," Revista de Biología Tropical, vol. 55, no. 2, pp. 347-364, 2007

[20] A. Ferrer and J. P. R. Cabral, "Epidemics due to pesticide contamination of food," Food Additives \& Contaminants, vol. 6, no. 1, pp. 95-98, 1989.

[21] L. R. Goldman et al., "Pesticide food poisoning from contaminated watermelons in California, 1985," Archives of Environmental Health: An International Journal, vol. 45, no. 4, pp. 229-236, 1990.

[22] European Parliament, Directive 2009/128/EC of the European Parliament and the Council of 21 October 2009 establishing a framework for Community action to achieve the sustainable use of pesticides. 2009.

[23] M. D. A. Morales and S. D. P. González, "Resultados del seguimiento de plagas y enfermedades en cultivos de cereales en Tenerife. Campaña 2009. Especial referencia al trigo," 2009.

[24] R. Gabarra i Ambert, J. Moliner, and J. Arnó Satorra, "Control integrado de plagas en invernaderos de tomate temprano en la isla de Menorca," Boletín de sanidad vegetal. Plagas, vol. 20, no. 2, pp. 501-509, 1994.

[25] A. Fereres Castiel, "Impacto del cambio climático sobre los insectos vectores de patógenos de plantas," Phytoma España: La revista profesional de sanidad vegetal, vol. 300, pp. 105-109, 2018.

[26] E. R. Hunt Jr, S. I. Rondon, P. B. Hamm, R. W. Turner, A. E. Bruce, and J. J. Brungardt, "Insect detection and nitrogen management for irrigated potatoes using remote sensing from small unmanned aircraft systems," in Autonomous Air and Ground Sensing Systems for Agricultural Optimization and Phenotyping, 2016.

[27] B. Stumph et al., "Detecting invasive insects with unmanned aerial vehicles," in Proceedings - IEEE International Conference on Robotics and Automation, 2019, vol. 20, pp. 648-654.

[28] R. R. Shamshiri, I. A. Hameed, S. K. Balasundram, D. Ahmad, C. Weltzien, and M. Yamin, "Fundamental Research on Unmanned Aerial Vehicles to Support Precision Agriculture in Oil Palm Plantations," Agricultural Robots-Fundamentals and Application, pp. 91-116, 2018.

[29] P. Psirofonia, V. Samaritakis, P. Eliopoulos, and I. Potamitis, "Use of Unmanned Aerial Vehicles for Agricultural Applications with Emphasis on Crop Protection: Three Novel Case - studies," International Journal of Agricultural Science and Technology, vol. 5, no. 1, pp. 30-39, 2017.

[30] Y. Li, C. Xia, and J. Lee, "Detection of small-sized insect pest in greenhouses based on multifractal analysis," Optik, vol. 126, no. 19, pp. 2138-2143, 2015.

[31] R. Boll, C. Marchal, C. Poncet, and L. Lapchin, "Rapid Visual Estimates of Thrips (Thysanoptera: Thripidae) Densities on Cucumber and Rose Crops," Journal of Economic Entomology, vol. 100, no. 1, pp. 225-232, 2007.

[32] Y. Li, C. Xia, and J. Lee, "Vision-based pest detection and automatic spray of greenhouse plant," IEEE International Symposium on Industrial Electronics, no. ISIE, pp. 920-925, 2009.

[33] S. R. Huddar, S. Gowri, K. Keerthana, S. Vasanthi, and S. R. Rupanagudi, "Novel algorithm for segmentation and automatic identification of pests on plants using image processing," in 3rd International Conference on Computing, Communication and Networking Technologies, ICCCNT 2012, 2012, pp. 1-5.

[34] H. D. D. Nguyen and C. Nansen, "Hyperspectral remote sensing to detect leafminer-induced stress in bok choy and spinach according to fertilizer regime and timing," Pest Management Science, 2020.

[35] B. Lumbierres, M. Eizaguirre Altuna, R. Albajes García, and X. Pons, "Plagas de los espacios verdes urbanos: bases para su control integrado," Boletín de sanidad vegetal. Plagas, vol. 32, no. 3, pp. 373-384, 2006.

[36] R. Ebesu, "Integrated pest management for home gardens: insect identification and control," Insect Pests, vol. 13, pp. 1-11, 2003.
[37] M. L. Flint, "Pests of the garden and small farm: A grower's guide to using less pesticide," UCANR Publications, vol. 3332, 2018.

[38] Ministerio de Agricultura, Pesca y Alimentación, "Guías de gestión integrada de plagas," 2014. [Online]. Available: https://www.mapa.gob. es/es/agricultura/temas/sanidad-vegetal/productos-fitosanitarios/guiasgestion-plagas/

[39] Ministerio de la Presidencia, Agencia Estatal Boletín Oficial del Estado. Real Decreto 1311/2012, de 14 de septiembre, por el que se establece el marco de actuación para conseguir un uso sostenible de los productos fitosanitarios. 2012, pp. 11-13.

[40] J. Moral de la Vega, "Dificultad para diseñar una Gestión Integrada de Plagas adecuada a los complicados sistemas agrarios actuales," PHYTOMA España, vol. 237, pp. 90-92, 2012.

[41] Ministerio de Agricultura, Pesca y Alimentación, "SIAR. Sistema de información agraria para el regadío," 1998. [Online]. Available: http:// eportal.miteco.gob.es/websiar/Inicio.aspx

[42] Ministerio de Política Territorial y Función Pública, "El sistema de información agroclimática para el regadío (SiAR)," datos.gob.es, 2019. [Online]. Available: https://datos.gob.es/es/blog/el-sistema-deinformacion-agroclimatica-para-el-regadio-siar

[43] D. C. Y. Vargas and C. E. P. Salvador, "Smart IoT gateway for heterogeneous devices interoperability," IEEE Latin America Transactions, vol. 14, no. 8, pp. 3900-3906, 2016.

[44] J. G. A. Barbedo, "Using digital image processing for counting whiteflies on soybean leaves," Journal of Asia-Pacific Entomology, vol. 17, no. 4, pp. 685-694, 2014.

[45] M. Qiao et al., "Density estimation of Bemisia tabaci (Hemiptera: Aleyrodidae) in a greenhouse using sticky traps in conjunction with an image processing system," Journal of Asia-Pacific Entomology, vol. 11, no. 1, pp. 25-29, 2008.

[46] C. Xia, T. S. Chon, Z. Ren, and J. M. Lee, "Automatic identification and counting of small size pests in greenhouse conditions with low computational cost," Ecological Informatics, vol. 29, no. P2, pp. 139-146, 2015.

[47] J. Cho et al., "Automatic identification of whiteflies, aphids and thrips in greenhouse based on image analysis," Iinternational Journal of Mathematics and Computers in Simulation, vol. 1, no. 1, pp. 46-53, 2007.

[48] L. O. Solis-Sánchez, J. J. García-Escalante, R. Castañeda-Miranda, I. Torres-Pacheco, and R. Guevara-González, "Machine vision algorithm for whiteflies (Bemisia Tabaci Genn) scouting under greenhouse environment," Journal of Applied Entomology, vol. 133, no. 7, pp. 546$552,2009$.

[49] L. O. Solis-Sánchez et al., "Scale invariant feature approach for insect monitoring," Computers and Electronics in Agriculture, vol. 75, no. 1, pp. 92-99, 2011.

[50] T. Liu, W. Chen, W. Wu, C. Sun, W. Guo, and X. Zhu, "Detection of aphids in wheat fields using a computer vision technique," Biosystems Engineering, vol. 141, pp. 82-93, 2016.

[51] R. G. M. Rupesh G. Mundada, "Detection and Classification of Pests in Greenhouse Using Image Processing," IOSR Journal of Electronics and Communication Engineering, vol. 5, no. 6, pp. 57-63, 2013.

[52] P. Boissard, V. Martin, and S. Moisan, "A cognitive vision approach to early pest detection in greenhouse crops," Computers and Electronics in Agriculture, vol. 62, no. 2, pp. 81-93, 2008.

[53] S. Poornima, S. Kavitha, S. Mohanavalli, and N. Sripriya, "Detection and classification of diseases in plants using image processing and machine learning techniques," in AIP Conference Proceedings, 2019, vol. 2095.

[54] J. Wang, Y. B. Chen, and J. P. Chanet, "An integrated survey in plant disease detection for precision agriculture using image processing and wireless multimedia sensor network," in Proceedings of the Internatinal Conference on Advanced in Computer, Electrical and Electronic Engineering ICACEEE, 2014, pp. 7-8.

[55] D. Jeric, A. Rustia, C. E. Lin, and T. Lin, "A Real-time Multi-class Insect Pest Identification Method using Cascaded Convolutional Neural Networks," in Proceedings of the 9th International Symposium on Machinery and Mechatronics for Agriculture and Biosystems Engineering ISMAB, 2018.

[56] V. Martin, S. Moisan, B. Paris, and O. Nicolas, "Towards a video camera network for early pest detection in greenhouses," in ENDURE International Conference, 2008, pp. 1-5. 
[57] D. J. A. Rustia, C. E. Lin, J. Y. Chung, Y. J. Zhuang, J. C. Hsu, and T. Te Lin, "Application of an image and environmental sensor network for automated greenhouse insect pest monitoring," Journal of Asia-Pacific Entomology, vol. 23, no. 1, pp. 17-28, 2020.

[58] B. Vijayalakshmi, C. Ramkumar, S. Niveda, and S. C. Pandian, "Smart Pest Control System in Agriculture," in IEEE International Conference on Intelligent Techniques in Control, Optimization and Signal Processing, INCOS 2019, 2019, pp. 1-4.

[59] H. Darmono, R. H. Y. Perdana, and W. Puspitasari, "Observation of greenhouse condition based on wireless sensor networks," IOP Conference Series: Materials Science and Engineering, vol. 732, no. 1, 2020.

[60] S. Rodríguez, T. Gualotuña, and C. Grilo, "A System for the Monitoring and Predicting of Data in Precision Agriculture in a Rose Greenhouse Based on Wireless Sensor Networks," Procedia Computer Science, vol. 121, pp. 306-313, 2017.

[61] C. Calderon-Cordova et al., "Wireless sensor network for real-time monitoring of temperature, humidity and illuminance in an orchid greenhouse," Iberian Conference on Information Systems and Technologies, CISTI, vol. 2018-June, no. June, pp. 1-7, 2018.

[62] M. E. Bayrakdar, "Qualified Underground Wireless Sensor," IEEE Sensors Journal, vol. 19, no. 22, pp. 10892-10897, 2019.

[63] M. Erazo-Rodas et al., "Multiparametric monitoring in equatorian tomato greenhouses (I): Wireless sensor network benchmarking," Sensors (Switzerland), vol. 18, no. 8, pp. 1-22, 2018.

[64] M. Mancuso and F. Bustaffa, "A Wireless Sensors Network for monitoring environmental variables in a tomato greenhouse," IEEE International Workshop on Factory Communication Systems - Proceedings, WFCS, pp. 107-110, 2006.

[65] J. Recasens and J. A. Conesa, Malas hierbas en plántula. Guía de identificación. Universitat de Lleida, 2009.

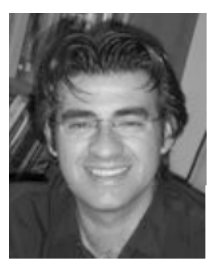

\section{Miguel Ángel López}

Has a degree in Engineering in Technical Engineering in Computer Systems from the University of Almería, graduates in Computer Engineering and Master in Softcomputing and Intelligent Systems from the University of Granada. Currently he is CTO. at Fidesol where performs diferent roles on the projects. His research focuses on distributed systems, management, integration and analysis of data, robotics, fuzzy logic systems, and the development of virtual reality environments for diferent purposes.

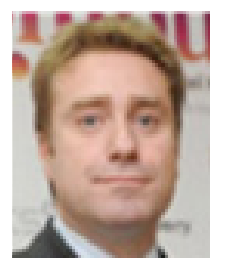

\section{Juan Manuel Lombardo}

Juan Manuel LombardoPhD in Computer Science from the Pontifical University of Salamanca, was graduated in Economics and Business Administration in the University of Granada, Spain, Diploma of Advanced Studies (DEA) in Economics from UNED, Research Sufficiency in Business Science from the Complutense University of Madrid and Diploma of Advanced Studies (DEA) in Sociology from the Pontifical University of Salamanca. He is CEO at Fidesol and Professor at Andalusia Business School. Dr. Lombardo is the author of numerous articles and research papers published in journals and books of national and international conferences. Visiting Professor at the Private Technical University of Loja (UTPL Ecuador), The National University of the Northeast (Argentina), University Francisco José de Caldas (Colombia), Catholic University of Colombia, Catholic University of Ibarra (Ecuador), University of Lisbon (Portugal) and National Engineering University (Peru). Member of the Knowledge Management committee of AEC (Spanish Association for Quality) and the Institute CICTES (Ibero-American Centre on Science, Technology and Society).

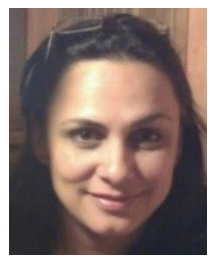

\section{Mabel López}

Has a degree of Computer Science Engineering. She is Knowledge Manager at Fidesol. Participates in the research and development strategy of this entity, technology transfer and analysis of technological trends, such as big data, internet of things, virtual reality, cognitive engines, machine learning, etc. Currently, she is involved in several $\mathrm{R} \& \mathrm{D}$ projects related to the mentioned technologies.

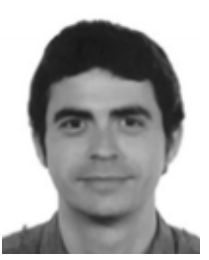

\section{David Álvarez}

David Alvarez received his Ph.D in Computer Science at the University of León, Spain in 2015, during which he worked on an Optical Caracter Recognition of handwritten documents. He then joined to the Research Group on Numerical Simulation and Scientific Calculus (SINUMCC) where he worked on Forest Fire Spread Simulation. He is now a member of the Research Group of Fundación del Software Libre (FIDESOL). His research interests include general computer vision, machine learning, image recognition and pattern recognition.

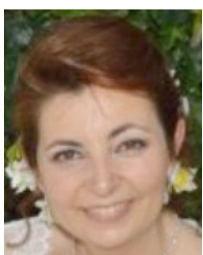

Susana Velasco

Has a Technical Engineer in Computer from the University of Granada. In the past, she worked in manufacturing, financial and service sector enterprises as software engineer and analyst programmer. Her research interests include quality assurance, software quality management systems, Ambient Intelligence (AmI) systems and devices, and new generation of ICT technologies.

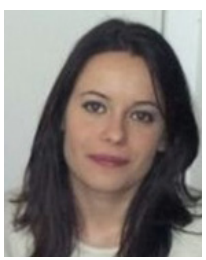

Sara Terrón

Sara Terrón $\mathrm{PhD}$ in Business and Economics Studies from University of Granada, was graduated in Building Engineering and Master's Degree in Integral Safety in Building from Universities of Seville and Granada. Author of several papers, at Fidesol she currently focuses her research on the technological area. 